\title{
Effect of Different Herbal Tea Preparations on the Color Stability of Glass lonomer Cements
}

This article was published in the following Dove Press journal:

Clinical, Cosmetic and Investigational Dentistry

\author{
Shehla Wasim Haque \\ Vidya-Saraswathi Muliya $\mathbb{D D}^{\prime}$ \\ Krishnaraj Somayaji ${ }^{1}$ \\ Kalyana- \\ Chakravarthy Pentapati (iD ${ }^{2}$ \\ 'Department of Conservative Dentistry \\ and Endodontics, Manipal College of \\ Dental Sciences, Manipal, Manipal \\ Academy of Higher Education, Manipal, \\ Karnataka, India; ${ }^{2}$ Department of Public \\ Health Dentistry, Manipal College of \\ Dental Sciences, Manipal, Manipal \\ Academy of Higher Education, Manipal, \\ Karnataka, India
}

Objective: To compare the color stability of the newer glass ionomer cements (GIC) when exposed to "Green tea" (GT), "Tulsi tea" (TT), and "Areca tea" (AT) using spectrophotometric analysis.

Materials and Methods: We selected commercially available GC Fuji IX GP EXTRA and Ketac Universal for this study. Eighty disc-shaped samples were made using a mold, which were immersed in the freshly prepared test solutions (distilled water, GT, TT, and AT) for 15 minutes per day for 60 days. The color estimation was done using a spectrophotometer.

Results: GC Fuji IX samples had a significantly higher mean difference in $\Delta \mathrm{E}$ value than Ketac Universal when immersed in GT, AT, and control $(\mathrm{P}<0.001,0.018$, and $<0.001)$, respectively. With GC Fuji IX, GT and AT stained more than TT and control solutions. Samples of Ketac Universal showed a significantly higher mean difference in $\Delta \mathrm{E}$ values when immersed in AT, followed by GT, TT, and control.

Conclusion: Within the study's limitations, we conclude that both the GICs exhibited staining over time on exposure to all the test solutions. Ketac Universal demonstrated lower staining potential than GIC Fuji IX GP Extra for GT and AT.

Keywords: staining, glass ionomer cement, dental, tea

\section{Introduction}

Restoring cervical lesions has been a challenge for dentists. The incidence of these lesions is known to increase with age. Glass ionomer cement (GIC) is the choice of restorative materials used to treat cervical lesions. They have superior retention due to chemical adhesion to the tooth structure, even in sclerotic dentin, and does not require removal of enamel margins for beveling as required in composites. Other characteristics include excellent biocompatibility, fluoride-releasing property, lower shrinkage, decreased microleakage, and acceptable aesthetics. ${ }^{1}$

Intrinsic or extrinsic discoloration of a material are two crucial causes among the many reasons for repeating the restoration. ${ }^{2}$ Causes for intrinsic discoloration include alterations in the restorative material's chemical structure due to physical and chemical conditions. Extrinsic discoloration is mainly due to the absorption and adsorption of exogenous stains. Studies have shown that diet is the leading cause for the development of extrinsic stains. ${ }^{3}$

Consumption of beverages like tea is a daily ritual for many people. Due to increased health consciousness, there is a change in the consumer preferences from conventional tea to Green tea (GT) and Tulsi tea (TT). They have added health benefits and are loaded with antioxidants and nutrients that improve immunity,

Correspondence: Vidya-Saraswathi Muliya Department of Conservative Dentistry and Endodontics, Manipal College of

Dental Sciences, Manipal, Manipal Academy of Higher Education, Manipal, Karnataka, India

Tel +9l 944-825-2360

Email vidya.saraswathi@manipal.edu 
reduce stress, enable fat loss, lower cholesterol, and aid in glycemic control among people with diabetes. ${ }^{4,5}$ Areca tea (AT) is another alternative that has many benefits like "anti-ulcer," "anti-aging," "hypo-lipidemic," "antidiabetic," along with enhanced "digestion" and "metabolism". ${ }^{6}$ Apart from their beneficial effects, tea preparations have substantial amounts of gallic acid, tannins, theaflavins, thearubigins, and theabrownins ${ }^{7,8}$ which can cause staining of teeth and restorative materials.

Newer GICs (GC Fuji IX GP Extra and Ketac Universal Glass Ionomer Restorative have been introduced in the market with increased fillers and are available in various shades. They offer superior mechanical and aesthetic properties and are indicated in the restoration of cervical lesions.

Literature shows that various beverages can alter the physical and aesthetic properties of GICs, undermining the quality of restorations that lead to their surface degradation and wear. Fuji IX showed the least color change compared to Fuji II LC, Dyract extra, and Filtek Z250. ${ }^{9}$ However, the discoloration potential of the above mentioned beverages on these restorative materials has not been much evaluated.

With this background, we aimed to compare the color stability of the newer GICs when exposed to different tea preparations using spectrophotometric analysis.

Null hypothesis: The newer GICs would have no difference in the color stability when exposed to different tea preparations.

\section{Materials and Methods}

Commercially available conventional GICs GC Fuji IX GP EXTRA (GC Corporation, Tokyo, Japan) and Ketac Universal Glass Ionomer Restorative (3M Deutschland $\mathrm{GmbH}$, Neuss, Germany) were selected for this study.

\section{Sample Preparation}

Eighty disc-shaped samples of GC Fuji IX $(n=40)$ and Ketac Universal $(\mathrm{n}=40)$ were prepared using a mold (diameter: $8 \mathrm{~mm}$; thickness: $2 \mathrm{~mm}){ }^{10}$ Cements were manipulated as per the manufacturers' guidelines and loaded into the mold, which was compressed between two glass plates lined by mylar strips to remove the excess and obtain smooth and flat surfaces. Once the materials were set, the discs were removed from the mold. ${ }^{10,11}$ All the samples were rehydrated by storing in distilled water for one day at room temperature, before the baseline color assessment. ${ }^{10}$
We randomly divided the samples of both the restorative materials into four subgroups (10 each) for immersing in the test solutions. They are distilled water (control), "Green tea" (Lipton, Hindustan Unilever Ltd, India), "Tulsi tea" (Tulsi Original, Organic India Pvt Ltd, India), and "Areca tea" (Mystic aromatics, India).

\section{Preparation of the Test Solutions}

The test solutions were prepared freshly every day using two tea bags ( $2 \mathrm{gm}$ each) in $300 \mathrm{~mL}$ of boiling water dipped for 3 minutes. ${ }^{2}$ The tea bags were removed and the test solution was cooled for 5 minutes.

\section{Immersion Regimen}

Each set $(\mathrm{n}=10)$ was immersed in the respective test solution in a container for 15 minutes/day for 60 days. After 15 minutes, the samples were stored in distilled water.

\section{Color Estimation Using Spectrophotometric Analysis}

The color estimation was done using a "Digital reflectance spectrophotometer (X-rite i1PRO Spectrophotometer and Profile maker Pro 5.0.10 software)" as described previously. ${ }^{12}$ Readings were obtained in triplicates, and the average value was obtained. ${ }^{13}$ The color assessment was calculated using the following equation: ${ }^{14}$

$$
\Delta \mathrm{E}^{*}=\left[\left(\Delta \mathrm{L}^{*}\right)^{2}+\left(\Delta \mathrm{a}^{*}\right)^{2}+\left(\Delta \mathrm{b}^{*}\right)^{2}\right]^{1 / 2}
$$

\section{Statistical Analysis}

All the analysis was done using MedCalc version 14 . A $p$-value of $<0.05$ was considered statistically significant. Normality was tested using the Shapiro Wilk test. Comparison of the mean $\Delta \mathrm{E}$ values between baseline and 60 days was done using Wilcoxon Signed rank test. The mean difference in $\Delta \mathrm{E}$ (baseline - 60 days) was compared between the two restorative materials using the Mann-Whitney $U$-test. The mean difference in $\Delta \mathrm{E}$ (baseline - 60 days) was compared using Kruskal Wallis ANOVA with post hoc Conover test.

\section{Results}

The data showed non-normal distribution hence nonparametric tests were used to compare $\Delta \mathrm{E}$ values. The mean $\Delta \mathrm{E}$ at 60 days was significantly higher than baseline in all the test solutions for both the GC Fuji IX and Ketac Universal (Table 1). The mean difference (Baseline 60 days) in $\Delta \mathrm{E}$ value was significantly higher in GC Fuji 
Table I Comparison of Mean $\Delta \mathrm{E}$ Between Baseline and 60 Days Concerning Various Test Solutions and Restorative Materials

\begin{tabular}{|c|c|c|c|}
\hline \multirow{2}{*}{ GC Fuji IX } & Baseline & 60 Days & \multirow{2}{*}{ p-value } \\
\cline { 2 - 3 } & Mean \pm SD & Mean \pm SD & \\
\hline Tulsi tea & $19.90 \pm 1.10$ & $24.10 \pm 0.99$ & 0.007 \\
Green tea & $20.40 \pm 1.26$ & $31.90 \pm 1.37$ & 0.005 \\
Areca tea & $20.40 \pm 0.97$ & $32.20 \pm 1.40$ & 0.005 \\
Control & $21.30 \pm 0.82$ & $25.00 \pm 0.67$ & 0.004 \\
\hline Ketac Universal & \multicolumn{3}{|}{} \\
\hline Tulsi tea & $15.00 \pm 1.25$ & $19.20 \pm 1.40$ & 0.005 \\
Green tea & $15.60 \pm 0.52$ & $21.60 \pm 1.07$ & 0.005 \\
Areca tea & $15.20 \pm 1.03$ & $24.50 \pm 2.12$ & 0.005 \\
Control & $15.50 \pm 0.71$ & $17.50 \pm 0.97$ & 0.005 \\
\hline
\end{tabular}

IX than Ketac Universal in GT, AT, and control solutions ( $\mathrm{P}<0.001,0.018$, and $<0.001)$, respectively. Among the GC Fuji IX samples, GT and AT stained more than TT and control solutions. Samples of Ketac Universal showed a significantly higher mean difference in $\Delta \mathrm{E}$ values when immersed in AT, followed by GT, TT, and control (Figure 1) (Table 2).

\section{Discussion}

Discoloration of restorations in esthetic areas of the mouth is one of the common reasons for replacing the restoration. Our study evaluated two new GICs which claim to offer superior aesthetics and physical properties. The long-term clinical performance and color stability of both these products are yet to be researched.

Our study showed that both the restorative materials stained significantly after the immersion regimen. It can be attributed to the softening and dissolution of the matrix

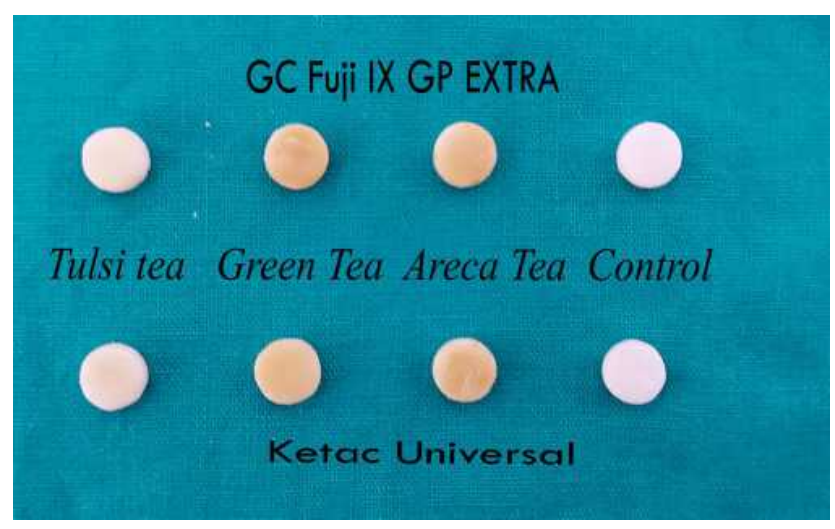

Figure I Representative images of staining on GC Fuji IX GP EXTRA and Ketac Universal after 60 days of exposure to various tea preparations.
Table 2 Comparison of Mean Difference of $\Delta E$ Among the Four Test Solutions and Two Restorative Materials

\begin{tabular}{|l|r|r|r|}
\hline Solution & $\begin{array}{r}\text { GC Fuji IX } \\
\text { Mean I SD }\end{array}$ & $\begin{array}{r}\text { Ketac Universal } \\
\text { Mean I SD }\end{array}$ & -value \\
\hline Tulsi tea [I] & $4.5 \pm 1.43$ & $4.3 \pm 1.7$ & 0.726 \\
Green tea [2] & $11.4 \pm 1.43$ & $6.3 \pm 1.25$ & $<0.001$ \\
Areca tea [3] & $11.9 \pm 1.6$ & $9.5 \pm 2.27$ & 0.018 \\
Control [4] & $4.1 \pm 0.32$ & $2 \pm 0.67$ & $<0.001$ \\
-value & $<0.001$ & $<0.001$ & \\
Post hoc test & $2,3>1,4$ & $3>2>1>4$ & \\
\hline
\end{tabular}

surrounding the glass particles and could result from the siliceous hydrogel layer's dissolution. ${ }^{15}$ This could result in a rough surface that has increased surface area for the adsorption of pigments, leading to staining. ${ }^{16}$ Overall maximum color change was seen in GIC Fuji IX GP Extra compared to Ketac Universal Glass Ionomer restorative. Studies have reported that benzoic acid in the copolymeric acid of Ketac Universal could produce a mechanical interlocking effect upon hardening, making it less hydrolytic and more color stable. ${ }^{17}$ Benzoic acidcontaining cements have been reported to have good chemical resistance in the oral environment. ${ }^{17}$ Color changes can also occur due to the leaching out of fluoride ions from the calcium fluorosilicate glass due to the ionic exchange between the material and the environmental solution, which affects its surface and structural integrity. ${ }^{18,19}$ Therefore, greater discoloration of GIC Fuji IX GP Extra could also occur due to its higher fluoride release potential than Ketac Universal. ${ }^{20}$

AT showed maximum staining in both the GICs, followed by GT, TT, and distilled water due to the high tannin content among the test solutions. Tannins are water-soluble polyphenols that impart tea its darker color and bitter taste. They have strong antioxidant properties that have various beneficial effects on health. However, one of their drawbacks is that they can lead to brownish discoloration of teeth and restorations when consumed over a prolonged period. ${ }^{21}$ Studies have shown that Areca nut's tannin content is up to $18 \%,{ }^{22,23} 3 \%$ to $13 \%$ in $\mathrm{GT}^{24},{ }^{24}$ and lowest concentration in TT $(0.9-2 \%) .{ }^{25}$ Previous studies evaluated composite restoration's color stability after exposure to few herbal health beverages like GT, AT, TT. All the tea preparations had clinical perceptible staining potential, and AT showed the highest staining potential, similar to results of the present study. ${ }^{12}$ 
Application of Fuji Coat LC has been recommended by the manufacturer to improve color stability of Fuji IX GP Extra restorations. However, Fuji IX coat LC does not come with Fuji IX GP Extra's standard packaging, and clinicians often do not opt for the additional purchase of such varnishes. As per the manufacturer's instruction, the application of Fuji coat LC is at the clinician's discretion. Also, Ketac Universal does not come with a matching preparation. The manufacturer claims this to be one of Ketac Universal's advantages, wherein one step of varnish application is eliminated. Hence to standardize the experiment, Fuji coat LC was not used over the specimens of Fuji IX GP Extra. Nonetheless, we ensured a good surface finish of the restorations using a mylar strip which was shown to be the smoothest. ${ }^{23}$ The use of mylar strip is also recommended by the manufacturer.

The $\Delta \mathrm{E}$ values between 0 to 2 represent imperceptible color changes, 2 to 3 represent just perceptible color changes on close observation. ${ }^{26}$ Values $\geq 3.3$ are noticeable with the naked eye and not acceptable clinically. ${ }^{27}$ In our study, GIC Fuji IX GP Extra, and Ketac Universal showed clinically perceptible changes in all the test solutions after 60 days of immersion. However, in distilled water least color change was seen for both materials but clinically noticeable only for GIC Fuji IX GP Extra. Previous studies have reported color changes with distilled water. ${ }^{13,28-30}$

Though our study results are difficult to extrapolate to invivo conditions due to other factors in the oral environment, this study highlights the color stability of the GICs when exposed to tea preparations. Future studies should explore the role of filler size, shape, and quantity on the color stability of these restorative materials.

\section{Conclusion}

All dental restorative materials have shown deterioration with time in the oral environment. Within the study's limitations, we can conclude that both the GICs exhibited staining over time on exposure to all the test solutions.

- Ketac Universal Glass Ionomer Restorative exhibited lower staining potential than GIC Fuji IX GP Extra for GT and AT.

- AT showed the highest discoloration potential in both the tested GICs.

Clinicians should consider the susceptibility of these restorative materials to stains due to the patients' dietary habits, while planning the restorations.

\section{Disclosure}

The authors reported no conflicts of interest for this work.

\section{References}

1. Francisconi LF, Scaffa PMC, de Barros VR, Coutinho M, Francisconi PAS. Glass ionomer cements and their role in the restoration of non-carious cervical lesions. J Appl Oral Sci. 2009;17 (5):364-369. doi:10.1590/S1678-77572009000500003

2. Bagheri R, Burrow MF, Tyas M. Influence of food-simulating solutions and surface finish on susceptibility to staining of aesthetic restorative materials. J Dent. 2005;33(5):389-398. doi:10.1016/j. jdent.2004.10.018

3. Padiyar N, Kaurani P. Colour stability: an important physical property of esthetic restorative materials. Int J Clin Dent Sci. 2010;1(1):81-84.

4. Mak JCW. Potential role of green tea catechins in various disease therapies: progress and promise. Clin Exp Pharmacol Physiol. 2012;39(3):265-273. doi:10.1111/j.1440-1681.2012.05673.x

5. Chacko SM, Thambi PT, Kuttan R, Nishigaki I. Beneficial effects of green tea: a literature review. Chin Med. 2010;5(1):13. doi:10.1186/1749-85465-13

6. Bhandare AM, Kshirsagar AD, Vyawahare NS, Hadambar AA, Thorve VS. Potential analgesic, anti-inflammatory and antioxidant activities of hydroalcoholic extract of areca catechu L. nut. Food Chem Toxicol. 2010;48(12):3412-3417. doi:10.1016/j. fct.2010.09.013

7. Kumari RV, Nagaraj H, Siddaraju K, Poluri RK. Evaluation of the effect of surface polishing, oral beverages and food colorants on color stability and surface roughness of nanocomposite resins. $J$ Int Oral Health. 2015;7(7):63-70.

8. Koech RK, Wanyoko J, Wachira F. Antioxidant, antimicrobial and synergistic activities of tea polyphenols. Int J Infect Dis. 2014;21:98. doi:10.1016/j.ijid.2014.03.631

9. E Sen T, Bayrak S, Guler AU, Tuloglu N. The effects of children's drinks on the color stability of various restorative materials. J Clin Pediatr Dent. 2009;34(2):147-150. doi:10.17796/ jcpd.34.2.953q255621436788

10. Bansal K, Saraswathi V, Acharya S. Effect of alcoholic and non-alcoholic beverages on color stability and surface roughness of resin composites: an in vitro study. J Conserv Dent. 2012;15(3):283. doi:10.4103/0972-0707.97961

11. Adusumilli H, Avula JSS, Kakarla P, Bandi S, Mallela GMK, Vallabhaneni K. Color stability of esthetic restorative materials used in pediatric dentistry: an in vitro study. J Indian Soc Pedod Prev Dent. 2016;34(3):233-237. doi:10.4103/0970-4388.186740

12. Patil A, Muliya V-S, Pentapati K-C, Kamath S. Effect of green, tulsi, and areca teas on the color stability of two composite resin materials an in vitro spectrophotometric analysis. Clin Cosmet Investig Dent. 2020;12:423-428. doi:10.2147/CCIDE.S276858

13. Nuaimi H, Ragab H. Effect of aggressive beverage on the color stability of different nano-hybrid resin based composite. Eur J Gen Dent. 2014;3(3):190. doi:10.4103/2278-9626.141666

14. Malekipour MR, Sharafi A, Kazemi S, Khazaei S, Shirani F. Comparison of color stability of a composite resin in different color media. Dent Res J (Isfahan). 2012;9(4):441-446. doi:10.4103/17353327.102781

15. Kaur S, Makkar S, Kumar R, Pasricha S, Gupta P. Comparative evaluation of surface properties of enamel and different esthetic restorative materials under erosive and abrasive challenges: an in vitro study. Indian J Dent. 2015;6(4):172. doi:10.4103/0975962x. 165047

16. Azer SS, Hague AL, Johnston WM. Effect of bleaching on tooth discolouration from food colourant in vitro. $J$ Dent. 2011;39(SUPPL. 3):e52-e56. doi:10.1016/j.jdent.2011.09.006 
17. Abdel Hamid DM, Mahmoud GM, El-Sharkawy FM, Abou Auf EA Effect of surface protection, staining beverages and aging on the color stability and hardness of recently introduced uncoated glass ionomer restorative material. Future Dent J. 2018;4(2):288-296. doi:10.1016/j.fdj.2018.05.004

18. Ren Y-F, Feng L, Serban D, Malmstrom HS. Effects of common beverage colorants on color stability of dental composite resins: the utility of a thermocycling stain challenge model in vitro. $J$ Dent. 2012;40(SUPPL. 1):e48-e56. doi:10.1016/j.jdent.2012.04.017

19. Hotwani K, Thosar N, Baliga S. Comparative in vitro assessment of color stability of hybrid esthetic restorative materials against various children's beverages. $J$ Conserv Dent. 2014;17(1):70-74. doi:10.4103/0972-0707.124154

20. Fuji IX GP Extra. Available from: http://www.gcaustralasia.com/ Upload/product/pdf/9/BROCHURE_FUJI_IX_GP_EXTRA.pdf. Accessed March 3, 2021.

21. Hattab FN, Qudeimat MA, Al-Rimawi HS. Dental discoloration: an overview. J Esthet Restor Dent. 1999;11(6):291-310. doi:10.1111/ j.1708-8240.1999.tb00413.x

22. Putri FM, Prihastanti E, Dwi Hastuti E. Tannin content of areca nut after nanochitosan coating on drying methods. Asian J Pharm Clin Res. 2020;13:75-78. doi:10.22159/ajpcr.2020.v13i4.36802

23. Erdemir U, Yildiz E, Eren MM, Ozsoy A, Topcu FT. Effects of polishing systems on the surface roughness of tooth-colored materials. $J$ Dent Sci. 2013;8(2):160-169. doi:10.1016/j. jds.2012.05.007
24. Khasnabis J, Rai C, Roy A. Determination of tannin content by titrimetric method from different types of tea. J Chem Pharm Res. 2015;7(6):238-241.

25. Borah R, Biswas S. Tulsi (Ocimum sanctum), excellent source of phytochemicals. Int $J$ Environ Agric Biotechnol. 2018;3 (5):1732-1738. doi:10.22161/ijeab/3.5.21

26. Vichi A, Ferrari M, Davidson CL. Color and opacity variations in three different resin-based composite products after water aging. Dent Mater. 2004;20(6):530-534. doi:10.1016/j.dental.2002.11.001

27. Fontes ST, Fernández MR, de Moura CM, Meireles SS. Color stability of a nanofill composite: effect of different immersion media. $J$ Appl Oral Sci. 2009;17(5):388-391. doi:10.1590/S167877572009000500007

28. De Alencar e Silva Leite ML, Da Cunha Medeiros e Silva FDS, Meireles SS, Duarte RM, Maciel AAK. The effect of drinks on color stability and surface roughness of nanocomposites. Eur J Dent. 2014;8(3):330-336. doi:10.4103/1305-7456.137640

29. Barutcigil Ç, Yildiz M. Intrinsic and extrinsic discoloration of dimethacrylate and silorane based composites. J Dent. 2012;40 (SUPPL. 1):e57-e63. doi:10.1016/j.jdent.2011.12.017

30. Tan BL, Yap AUJ, Ma HNT, Chew J, Tan WJ. Effect of beverages on color and translucency of new tooth-colored restoratives. Oper Dent. 2015;40(2):E56-E65. doi:10.2341/149027-L

\section{Publish your work in this journal}

Clinical, Cosmetic and Investigational Dentistry is an international, peer-reviewed, open access, online journal focusing on the latest clinical and experimental research in dentistry with specific emphasis on cosmetic interventions. Innovative developments in dental materials, techniques and devices that improve outcomes and patient satisfaction and preference will be highlighted. The manuscript management system is completely online and includes a very quick and fair peer-review system, which is all easy to use. Visit http://www.dovepress.com/testimonials.php to read real quotes from published authors. 